\title{
An Infratemporal Meningioma: A Diagnostic Dilemma
}

\author{
Arlinder Kaur ${ }^{1}$, Rofiah $\mathrm{Ali}^{1}$, Effat Omar ${ }^{2,3}$, Hilwati Hashim ${ }^{4 *}$ \\ 1. Department of Radiology, Hospital Sungai Buloh, Malaysia \\ 2. Centre for Pathology Diagnostic and Research Laboratories, Faculty of Medicine, Universiti Teknologi MARA, Malaysia \\ 3. Institute for Pathology, Laboratory and Forensic Medicine (iPPerForm), Faculty of Medicine, Universiti Teknologi MARA, Malaysia \\ 4. Department of Radiology, Faculty of Medicine, Universiti Teknologi MARA, Malaysia \\ * Correspondence: Hilwati Hashim, Department of Radiology, Faculty of Medicine, Universiti Teknologi MARA (UiTM), Sg. Buloh \\ Campus, Jalan Hospital, $47000 \mathrm{Sg}$. Buloh, Selangor, Malaysia \\ (근ilwa167@salam.uitm.edu.my)
}

Radiology Case. 2021 Jan; 15(1):1-10 :: $\quad$ DOI: 10.3941/jrcr.v15i1.3898

\begin{abstract}
A 46-year-old male presented with painless, recurrent bilateral ear discharge and an enlarging right temporal swelling. There were no neurological deficits. Imaging revealed an enhancing, soft tissue mass at the right infratemporal region involving the right temporalis muscle with a small, enhancing intradural component and associated hyperostosis of the greater wing of the right sphenoid bone. Tumour debulking of the right temporalis tumour was performed. Tumour invasion of the right temporalis muscle was noted intraoperatively. Histopathological result was consistent with fibrous meningioma WHO Grade 1 involving surgical resection margins. Follow-up MRI revealed residual right temporal extracranial component. Thus, plans were made for a second stage tumour debulking, however at time of writing, surgery had not been performed. This case highlights the differing appearances of the common meningioma occurring extracranially with elaboration of its differential diagnosis and management.
\end{abstract}

\section{CASE REPORT}

\section{CASE REPORT}

A 46-year-old male with a history of recurrent bilateral serous ear discharge presented with painless, progressively worsening right temporal swelling for over a year. There was no previous history of trauma. Examination revealed a $4 \mathrm{x}$ $5 \mathrm{~cm}$, firm, non-tender, non-fluctuant, right temporal swelling. There was also subtotal perforation of the right tympanic membrane. Other otorhinolaryngological examinations were unremarkable. There was no hearing loss. Neurological and eye examinations were intact.
Magnetic resonance imaging (MRI) and Computed tomography (CT) of the neck were performed. Magnetic resonance imaging showed a lobulated, homogenously enhancing, infiltrative right temporal mass measuring approximately $5 \times 5 \times 6 \mathrm{~cm}$ with a small intradural component (Figure 1, 2, 3). Both intradural and extradural components showed similar signal intensities, appearing hypointense on $\mathrm{T} 1$-weighted and heterogeneously isointense on T2-weighted sequences. Computed tomography showed hyperostotic bony changes at the right sphenoid bone (Figure 4). There was no intraorbital extension of the tumour. Initial radiological 
impression was of an aggressive sphenoid wing soft tissue tumour with local infiltration.

Tumour debulking was subsequently performed. Intraoperatively, there was fullness of the right temporal region. A whitish to pale tumour was seen overlying the right temporalis muscle and eroding into it with a preserved galea. The temporalis muscle as well as the tumour were then resected. No complications were encountered during the surgery. The patient recovered well with no new symptom or cranial nerve palsy.

Histopathology of skeletal muscle showed presence of spindle-shaped cells and a few whorl formations, consistent with Fibrous Meningioma, WHO Grade 1 with involvement of the surgical resection margins (Figure 5).

An MRI post surgery showed residual right temporal extracranial component, measuring approximately $3 \times 4 \times 3$ $\mathrm{cm}$. The right temporal intradural component remained similar. (Figure 6). At time of writing, second stage of tumour debulking was not performed. Apart from occasional headaches, patient has no other complaints.

\section{DISCUSSION}

\section{Etiology \& Demographics:}

Meningiomas account for approximately $15-18 \%$ of all primary brain tumours. It originates from meningocytes or arachnoid cap cells, that line the meninges. Extracranial extension of meningioma is uncommon, occurring in up to $2 \%$ of meningiomas $(1,2)$. There is a female predominance of meningiomas, with a median age of occurrence at 40 to 60 years old. It may involve the scalp, ear, temporal bone, sinonasal tract, orbit, the outer table of calvarium and the parotid-pterygoid region to name a few. These tumours pose significant diagnostic challenges owing to the presence of both intradural and extracranial components.

Hoye et al postulated four theories of extracranial extension pathways (3) :

TYPE A: Direct extracranial extension of a primary tumour via foraminae, sutures, etc.

TYPE B: Extracranial growth from arachnoid cells within sheaths of cranial nerves

TYPE C: Extracranial growth from embryonic rests of arachnoid without foraminal or cranial nerve communication

TYPE D: Distant metastases of intracranial meningioma

In our case, there is a demonstrable communication between the extracranial and intradural components via the pterygopalatine fossa and foramen ovale which fits into the Hoye et al Type A pathway. The pterygopalatine fossa transmits the maxillary division of the trigeminal nerve $(\mathrm{Vb})$ and communicates with the infratemporal fossa via the pterygomaxillary fissure. The foramen ovale forms part of the roof of the infratemporal fossa. It transmits the mandibular division of the trigeminal nerve $(\mathrm{Vc})$.

\section{Clinical \& Imaging findings:}

Presentation typically reflects the anatomical site of involvement and due to mass effect from the extracranial component $(2,4)$. Common symptoms include aural fullness and otalgia, hearing loss, tinnitus, otitis media, facial nerve palsy, headaches and speech problems.

Imaging is an important component of investigation. Radiologically, meningiomas are avidly enhancing, extra-axial tumours with a broad dural base and adjacent hyperostosis. On CT, tumours are commonly isodense to the normal brain parenchyma. 20-30\% may have some calcification. Magnetic resonance imaging shows tumour to be isointense to grey matter on $\mathrm{T} 1$ and T2-weighted images with avid and homogenous contrast enhancement. Magnetic resonance spectroscopy(MRS) spectrum of typical meningiomas exhibit a high choline peak (Cho) with low or absent $\mathrm{N}$ acetylaspartase (NAA) and creatine $(\mathrm{Cr})$. A relatively specific marker for meningiomas, is the presence of alanine, particularly Alanine resonance at $3.8 \mathrm{ppm}$ in long-TE sequences. Absence of a lipid or lactate peak helps distinguish meningiomas from its other more malignant mimics i.e. metastases. Magnetic resonance perfusion study of meningiomas generally demonstrate increased relative cerebral blood volume (rCBV) and relative cerebral blood flow $(\mathrm{rCBF})$. Both intradural and extradural components share similar radiological characteristics. Therefore, presence of both an extradural mass and an adjacent enhancing intradural component should raise the suspicion of an extracranial meningioma. In certain instances, as in ours, the bulk of the tumour is extracranial, with a minor intradural component. Imaging is required to delineate the extent of both components. Magnetic resonance imaging aids in this process, owing to its better spatial resolution.

\section{Treatment \& Prognosis:}

Surgical resection is the mainstay of treatment. However, complete resection of both the extradural and intradural components is challenging due to the large tumour size and its poorly delineated margins. A multidisciplinary approach is thus required, involving both neurosurgical and otorhinolaryngological expertise (5). Radiotherapy and radiofrequency ablation of large extracranial meningiomas can be used to reduce tumour bulk prior to surgery and to reduce symptoms in palliative cases (6). Complete resection of these tumours are accompanied by a high rate of complications, including cranial nerve palsies, facial disfigurement, ophthalmoplegia and visual disturbances. In our case, there is a risk of perineural spread of the tumour via the cranial nerves, along foramen ovale and the pterygopalatine fossa. Recurrence or growth of tumour may involve the nasal cavity, orbit and middle cranial fossa.

Extracranial meningiomas are associated with a higher rate of recurrence. The extent of surgical resection and the large size of tumour, influences recurrence of tumour (Table 1). Recurrence of infratemporal meningiomas occur along the margins of previous resection and middle cranial fossa or along margins of resected bone (7). Infratemporal meningiomas have the propensity to involve the skeletal muscle, trigeminal nerve (CN V), mucosa of paranasal sinuses and/or nasopharynx (7). 


\section{Differential Diagnosis:}

Extracranial meningiomas pose significant diagnostic challenges to radiologists owing to the presence of both intradural and extracranial components. Several other entities may share similar radiological findings, mimicking meningiomas. Differentials for extracranial meningiomas include solitary fibrous tumour/hemangiopericytomas, dural metastases, primary dural lymphoma, neurosarcoidosis and chondrosarcomas.

Solitary fibrous tumour/hemangiopericytomas have been designated as a single entity based on the latest 2016 WHO classification of tumours of the central nervous system.

Within this classification, tumours are divided into Grades I, II and III with significant overlap of the radiological findings in all three tumour subtypes.

Grade I tumours were previously known as solitary fibrous tumours (SFT). Solitary fibrous tumours are frequently encountered in the pleural cavity with rare intracranial occurrence. These are tumours of low cellularity and high collagen content. As with meningiomas, presentation varies according to site of tumour. Common sites are along the falx, occipital and spinal dura. On CT, SFTs are well defined hyperdense masses with variable amounts of calcification and adjacent bony erosions. Tumours are generally isointense on T1-weighted MRI. On T2-weighted MRI, there are mixed areas of hypo- and hyperintensity, giving a 'yin-yang' appearance, which is typical of SFTs. There is heterogenous contrast enhancement of mainly the T2 hypointense areas. Tumours may show presence of a dural tail, however less frequent in comparison to meningiomas. Surgical resection is mostly curative. Radiotherapy may be performed in incomplete resection and recurrence.

Its more cellular, aggressive form is classified as a Grade II tumour, formerly known as a hemangiopericytoma. Hemangiopericytomas are rare, highly vascular tumours that occur at an earlier age than typical meningiomas. Hemangiopericytomas tend to recur and frequently metastasize to lungs, liver and bone. Typically, hemangiopericytomas are hyperdense on CT with heterogenous enhancement. Unlike meningiomas, these lesions cause erosion of the adjacent bone without hyperostosis or calcification. Lesions are isointense to grey matter on both T1 and T2 weighted MRI with heterogenous contrast enhancement. In MR Spectroscopy, hemangiopericytomas demonstrate elevated Choline levels with absence/low lipid, NAA and creatine, similar to meningiomas. In most instances, no Alanine peak was detected. Dural tail is present in most cases with either a broad or narrow dural base. There are prominent internal flow voids owing to the vascular nature of the mass. Pre-operative embolization is performed prior to surgical resection. Postoperative radiotherapy may add benefit.

Grade III tumours are highly mitotic and were previously designated as anaplastic hemangiopericytomas. Haemorrhage, necrosis and cystic areas are more common in the anaplastic form. Differentiation of all three grades of tumour is by histological examination.
One of the differential diagnosis for dural based lesion is dural metastases. Patients presenting with dural metastases are usually in advanced stages of disease. Breast cancer has the highest rate of dural metastases, followed by prostate, lung and cancer of the head and neck. In children, neuroblastoma metastases are the most common. Dural metastases occur as an extension from intracranial metastases, via hematogenous or lymphatic seeding. Plain radiographs and CT show either osteolytic, sclerotic or mixed pattern of lesions with poorly delineated margins. Metastases tend to follow radiological characteristics of the primary tumours, are typically isohypointense on T1- weighted MRI and iso-hyperintense on T2-weighted MRI with vivid enhancement. Magnetic resonance spectroscopy (MRS) results are similar to meningiomas, with a high Choline peak, low creatine and NAA levels. However, in contrary to meningiomas, metastases tend to exhibit a lactate and/or lipid peak. There may be solitary or multiple lesions. Patients with a solitary resectable lesion may undergo surgical resection, however the most common treatment is conventional radiation therapy. Chemotherapy is reserved for chemosensitive tumours and may be performed in addition to radiotherapy. Presence of a primary tumour or a previous history of malignancy should direct the radiologist to a more definite diagnosis of dural metastases.

Another differential for a dural based lesion is primary dural lymphoma which is a subtype of primary central nervous system (CNS) lymphoma. Most primary dural lymphomas are mucosa associated lymphoid tissue (MALT) lymphomas. It shares similar radiological characteristics with meningiomas, however its occurrence is sparse (less than $1 \%$ of all CNS lymphomas). Its occurrence has been reported among middleaged women. As with typical lymphomas, tumours are hyperdense on non-enhanced CT with presence of vasogenic edema. There may be single or multiple extra-axial masses. Bone setting shows a permeative pattern of osteolysis, with little bone destruction. Lesions are isointense on T1-weighted and iso-hypointense on T2-weighted sequences. There is homogenous enhancement of the mass with an accompanying dural tail. Extension of dural lesions to the scalp and subcutaneous tissue have been reported. Prognosis is favourable with surgery and radiotherapy.

Neurosarcoidosis is another differential diagnosis of dural lesion. Isolated neurosarcoidosis is extremely rare with regards to its systemic manifestation. Patients present with variable, non-specific symptoms. Middle aged females remain the main demographic group. Neurosarcoid lesions may involve the leptomeninges, pituitary, hypothalamus, parenchyma, dura and cranial nerves. Dural involvement is in the form of diffuse dural thickening or focal dural masses. Computed tomography has low sensitivity and specificity for detection of lesions. Lesions are typically hyperdense and hydrocephalus is a common occurrence. On MRI, lesions are isointense on $\mathrm{T} 1$ and predominantly hypointense on $\mathrm{T} 2$ weighted images with homogenous enhancement. Hypointensity of lesions on T2-weighted MRI serves as a clue to the diagnosis of neurosarcoidosis, however certain calcified tumours i.e. calcified meningiomas may show similar MRI features. Diagnosis of sarcoidosis is usually established via biopsy, depicting typical non-caseating granulomas with absence of organisms. However, in the case of neurosarcoidosis, biopsy is not possible. Diagnosis is based on 
clinical and imaging findings with evidence of systemic sarcoidosis. Typical chest radiograph findings, gallium scan findings or elevated serum angiotensin-converting enzyme levels provide a more definitive diagnosis. High dose steroid therapy is mandatory, though there is a high rate of progression and recurrence after treatment.

A differential diagnosis for an infratemporal mass is chondrosarcoma. Chondrosarcomas are locally aggressive tumours with rare occurrence in the skull. Most intracranial chondrosarcomas arise from the skull base, rarely from dura mater, choroid plexus, or the brain parenchyma. Chondrosarcomas can also be associated with Ollier disease and Maffucci syndrome. As with typical chondrosarcomas, CT shows lytic bone lesions with chondroid pattern of calcification i.e. ring and arc. Lesions are hypointense on T1weighted and hyperintense on T2-weighted MRI with heterogenous contrast enhancement. Susceptibility weighted imaging (SWI)/ Gradient echo (GRE) sequences show low signal intensities of calcification. Lesions are accompanied by pressure erosions of the adjacent bone, due to the slow growing nature of the tumour. Lesions are treated by surgical resection.

\section{Conclusion:}

Extracranial meningiomas, in particular infratemporal meningiomas are rare. These tumours may mimic various other pathologies, thus delaying diagnosis and treatment. A high index of suspicion for extracranial meningiomas is crucial to ensure accurate diagnosis prior to treatment and to minimize post-operative complications.

\section{TEACHING POINT}

Extracranial meningiomas share similar radiological characteristics with its more common intracranial counterpart. Presence of a significant extracranial component may complicate the diagnosis, thus an understanding of the extension pathways and imaging features particularly of infratemporal meningiomas will help in differentiating tumours of rare locations.

\section{REFERENCES}

1. Friedman CD, Costantino PD, Teitelbaum B, Berktold RE, Sisson GA, Sr. Primary extracranial meningiomas of the head and neck. The Laryngoscope. 1990;100(1):41-8. PMID: 2104554

2. Ricciardiello F, Fattore L, Liguori ME, Oliva F, Luce A, Abate $\mathrm{T}$, et al. Temporal bone meningioma involving the middle ear: A case report. Oncol Lett. 2015;10(4):2249-52. PMID: 26622828

3. Hoye SJ, Hoar CS, Murray JE. Extracranial meningioma presenting as a tumor of the neck. American journal of surgery. 1960;100:486-9. PMID: 13716296

4. Chang CY, Cheung SW, Jackler RK. Meningiomas presenting in the temporal bone: the pathways of spread from an intracranial site of origin. Otolaryngology--head and neck surgery : official journal of American Academy of Otolaryngology-Head and Neck Surgery. 1998;119(6):658-64. PMID: 9852544

5. Mourad M, Chan D, Ducic Y. Surgical Management of Extracranial Meningiomas Arising in the Head and Neck. Journal of oral and maxillofacial surgery : official journal of the American Association of Oral and Maxillofacial Surgeons. 2016;74(9):1872-8. PMID: 27087283

6. Kato A, Fujimoto Y, Hashimoto N, Taniguchi M, Kinoshita M, Hirayama A, et al. Radiofrequency thermal ablation for recurrent meningioma extending extracranially. Acta neurochirurgica. 2005;147(5):543-50; discussion 50. PMID: 15812596

7. Pieper DR, Al-Mefty O. Management of intracranial meningiomas secondarily involving the infratemporal fossa: radiographic characteristics, pattern of tumor invasion, and surgical implications. Neurosurgery. 1999;45 2:231-7; discussion 7-8. PMID: 10449066

8. Simpson D. The recurrence of intracranial meningiomas after surgical treatment. J Neurol Neurosurg Psychiatry. 1957;20(1):22-39. PMID: 13406590 


\section{FIGURES}

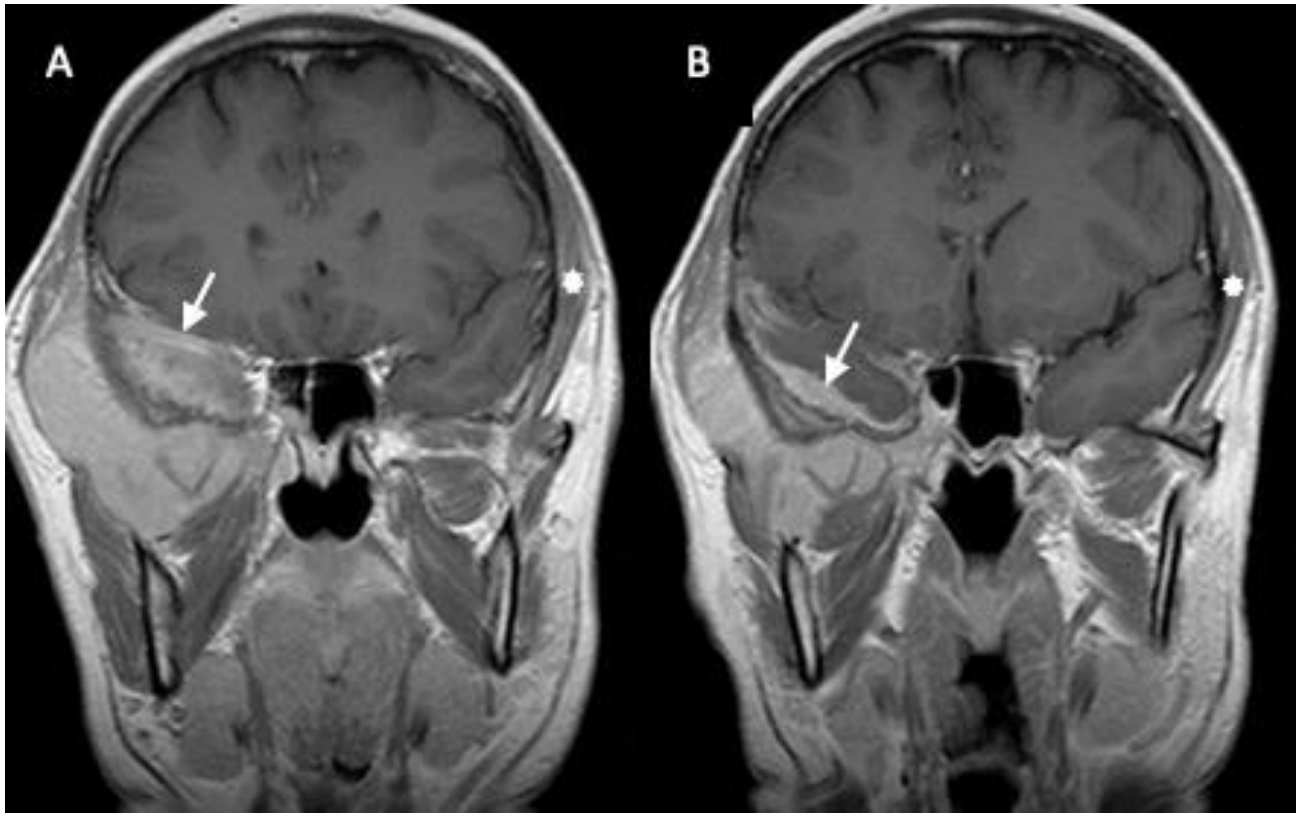

Figure 1: 46-year-old male with right infratemporal meningioma

Findings: Coronal T1-weighted MR images with gadolinium (A and B) shows an enhancing intradural component of the right temporal mass (arrow). Its extracranial component is seen infiltrating the right temporal muscle. Normal left temporal muscle (asterisk).

Technique: 1.5 Tesla Siemens Magnetom Symphony scanner. (A and B) Coronal T1W with gadolinium, TR 470, TE 8.7, 5.0mm slice thickness, contrast material Magnevist (5mls)

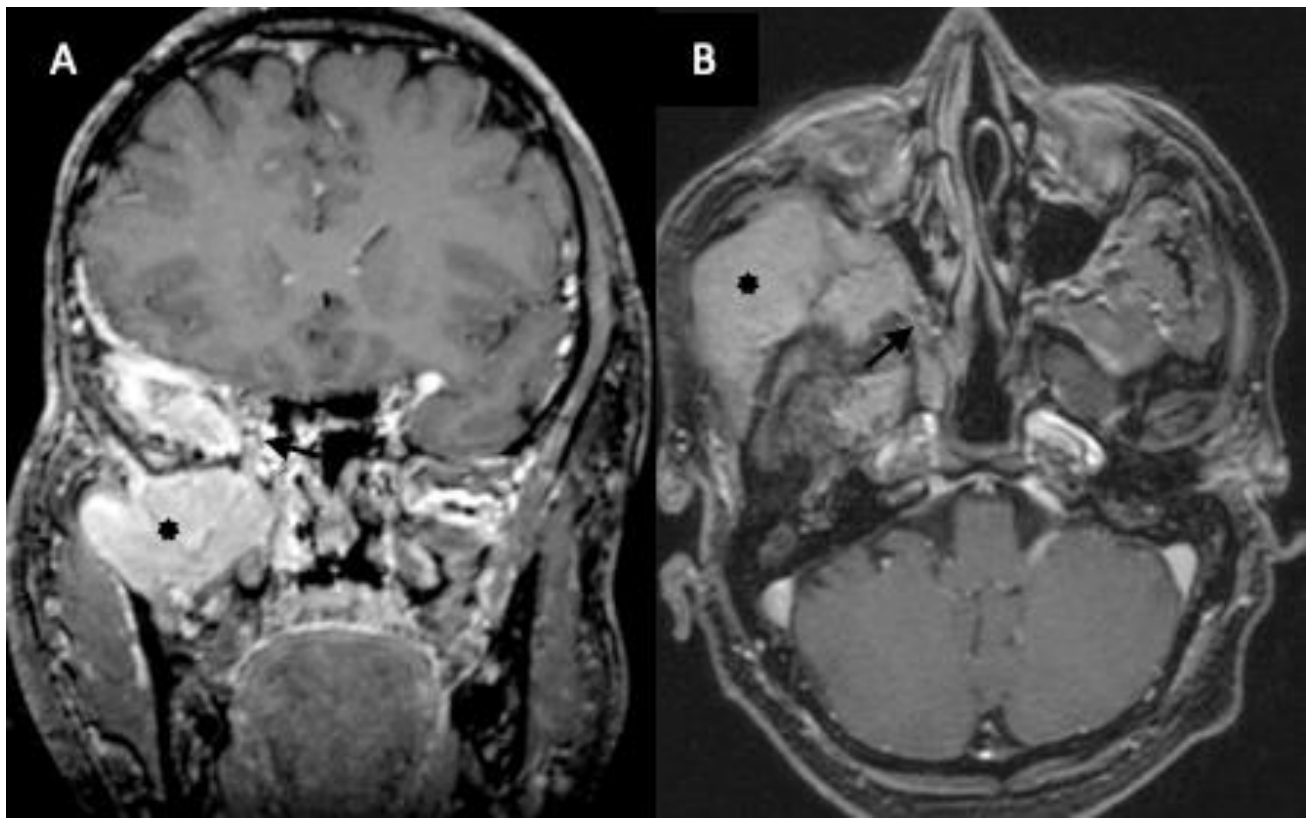

Figure 2: 46-year-old male with right infratemporal meningioma

Findings: T1-weighted MR images with gadolinium. (A) coronal T1-weighted MR image with gadolinium shows extension of the intradural tumour via the pterygopalatine fossa (black arrow). (B) axial T1-weighted MR image with gadolinium showing tumour within the pterygopalatine fossa (arrow), note the large enhancing infratemporal component (asterisk).

Technique: 1.5 Tesla Siemens Magnetom Symphony scanner. (A) Coronal T1W with gadolinium, TR 9.8, TE 4.8, 1.0mm slice thickness, contrast material Magnevist (5mls); (B) Axial T1W with Gadolinium, TR 590, TE 11, 5.0mm slice thickness, contrast material Magnevist (5mls). 


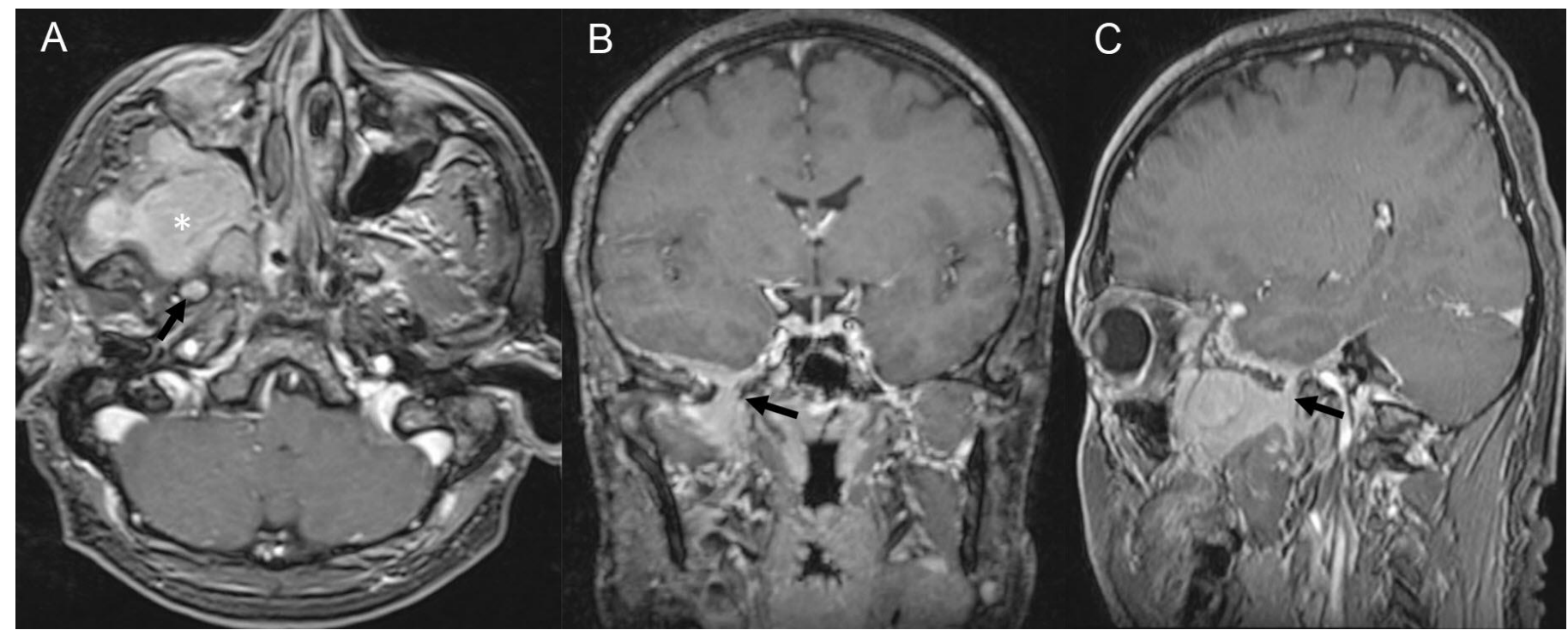

Figure 3: 46-year-old male with right infratemporal meningioma

Findings: T1-weighted MR images with gadolinium. (A) axial image, enhancing component within the right foramen ovale (arrow) with right infratemporal component (asterisk) expanding towards the right maxillary sinus. (B) coronal and (C) sagittal images showing extension of tumour via the foramen ovale (arrow).

Technique: 1.5 Tesla Siemens Magnetom Symphony scanner. (A) Axial T1W with gadolinium, TR 590, TE 11, 5.00mm slice thickness, contrast material Magnevist $(5 \mathrm{mls})$; (B) Coronal T1W with gadolinium, TR 590, TE 11, 5.00mm slice thickness, contrast material Magnevist (5mls); (C) Sagittal T1W with gadolinium, TR 470, TE 8.7, 5.0mm slice thickness, contrast material Magnevist (5mls).

Figure 4 (right): 46-year-old male with right infratemporal meningioma

Findings: Axial CT image with bone window showing hyperostosis of the greater wing of the right sphenoid bone.

Technique: High resolution CT of the temporal bone on axial section, bone setting. $0.6 \mathrm{~mm}$ slice thickness at $102 \mathrm{mAs}$ and $120 \mathrm{kV}$.

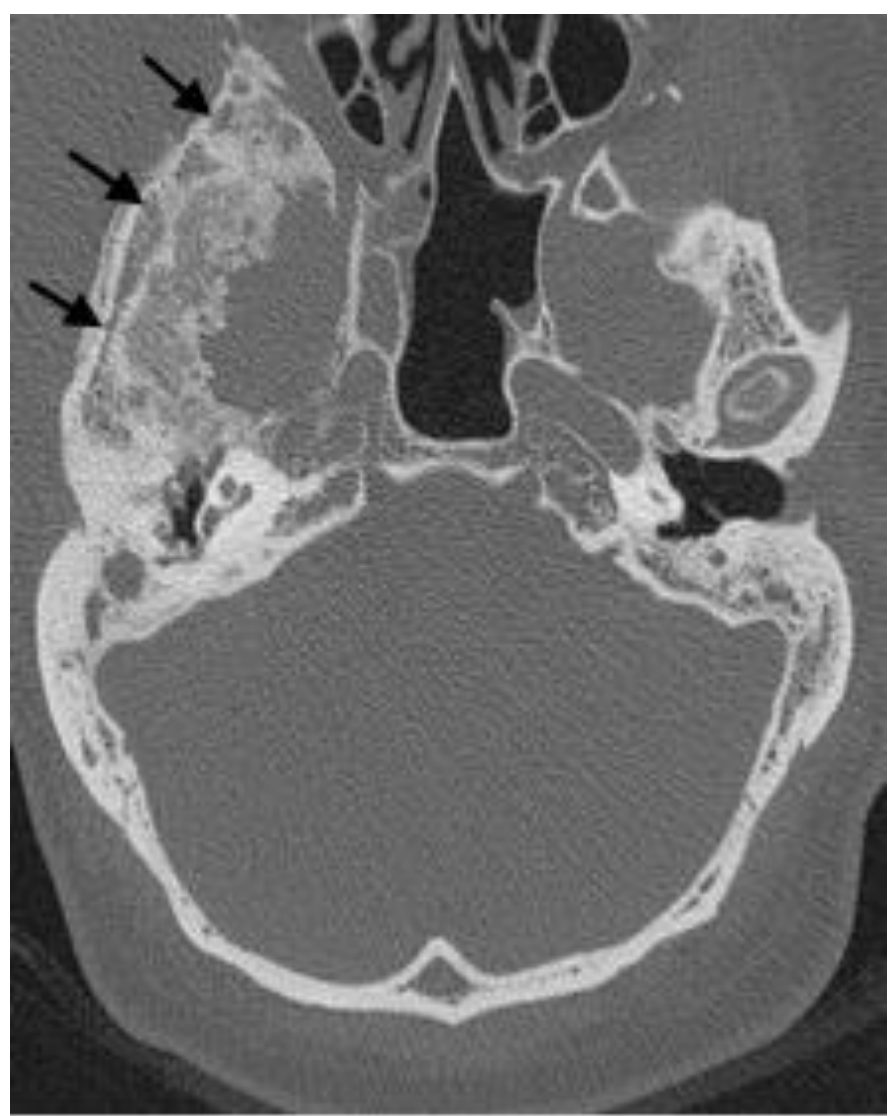




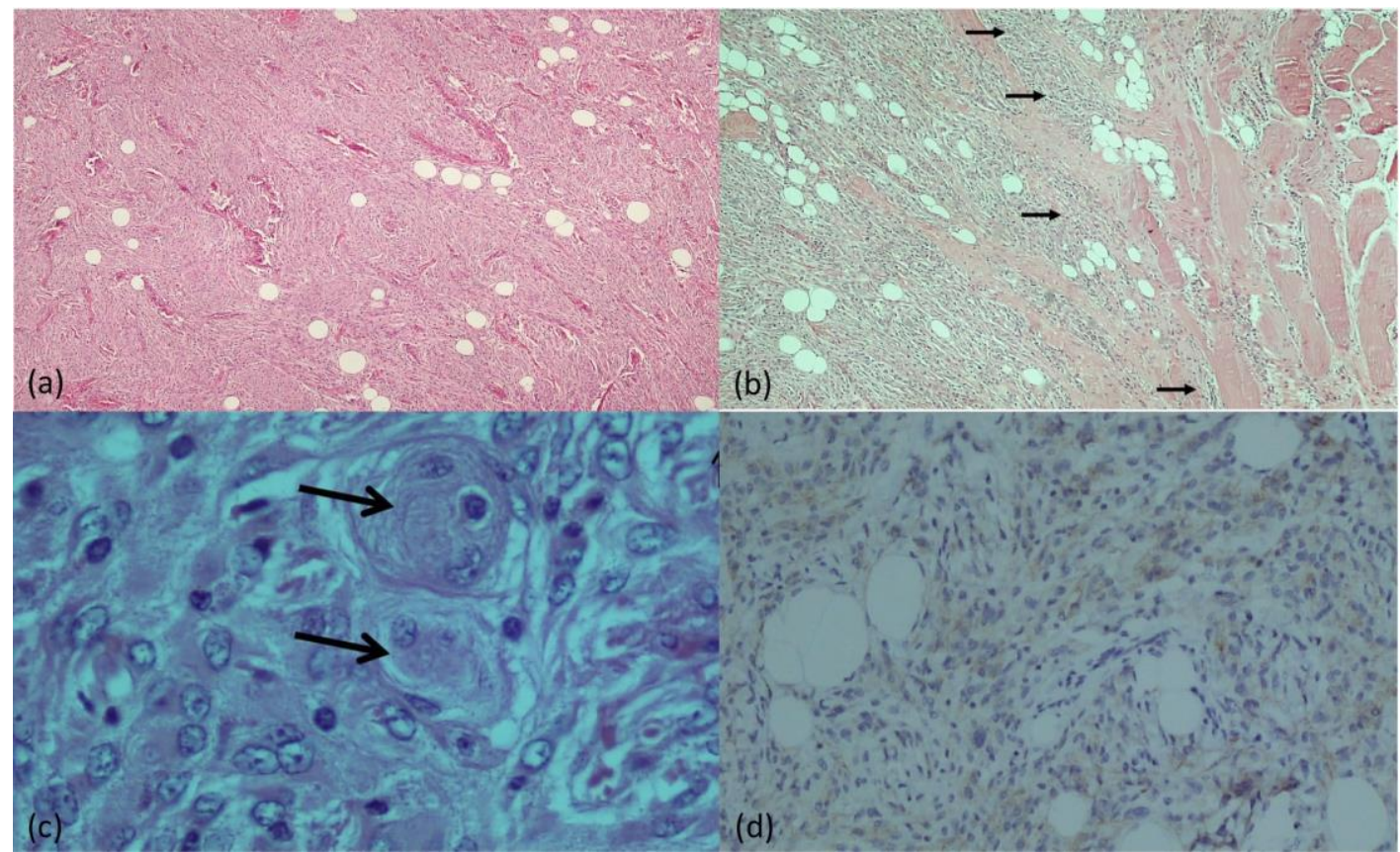

Figure 5: 46-year-old male with right infratemporal meningioma

Findings: (a) low power view of the tumour area showing sheets and fascicles of spindle-shaped cells (H\&E; X40 magnification). (b) the edge of the tumour is ill defined; the cells are seen to infiltrate the adjacent adipose tissue and skeletal muscle bundles (arrows) (H\&E; X40 magnification). (c) focal whorl formation (arrows) is seen, mitosis is low (1 per 10 high power fields), necrosis is not seen (H\&E; X200 magnification). (d) immunohistochemistry shows patchy epithelial membrane antigen (EMA) positivity (picture). The cells are also positive for vimentin and S100, but are negative for CD-34, melan-A, HMB-45, SMA and desmin.

Technique: Light microscopy. (a) Hematoxylin-eosin stain; X40 magnification. (b) Hematoxylin-eosin stain; X40 magnification. (c) Hematoxylin-eosin stain; X200 magnification.

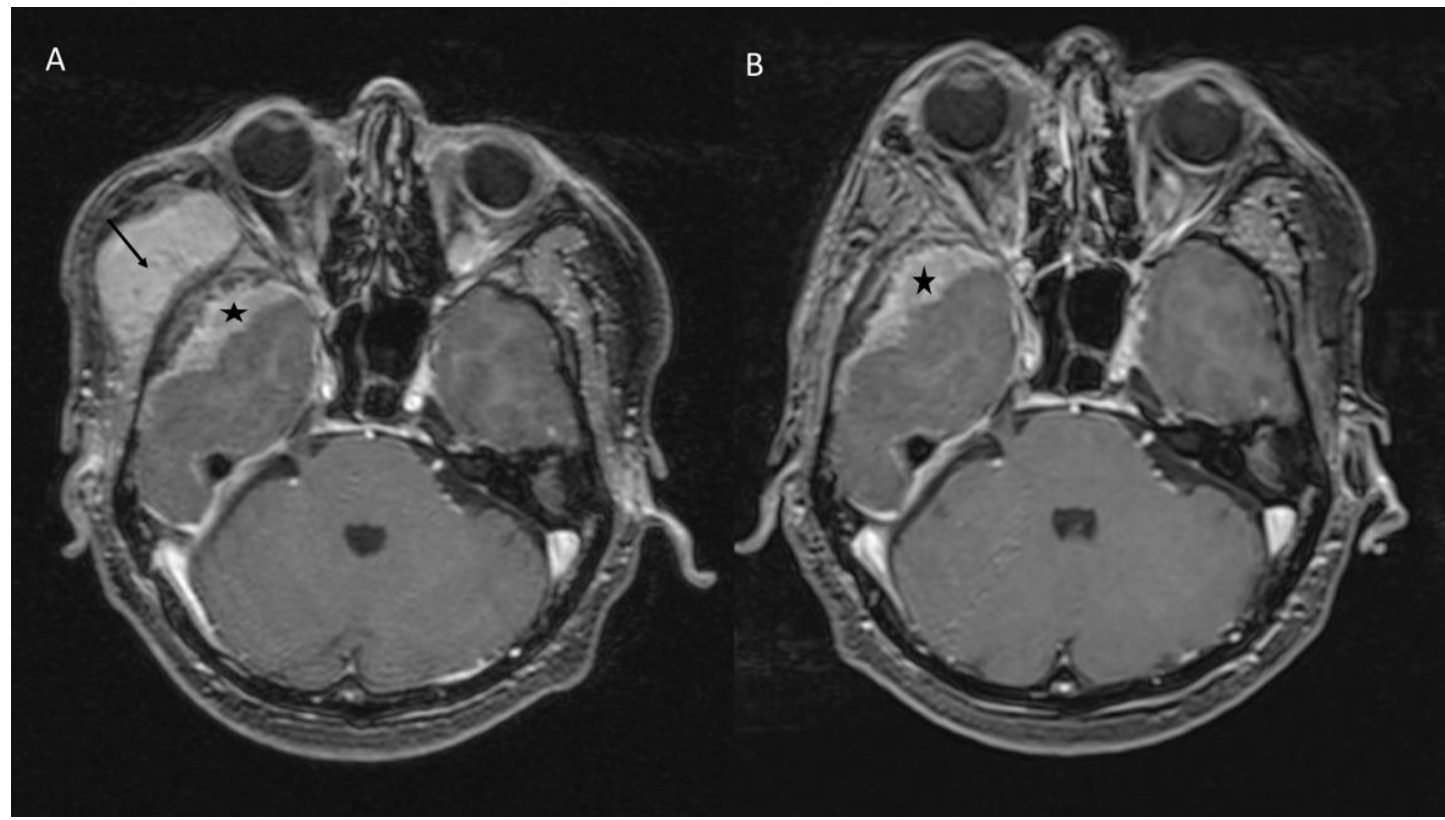

Figure 6: 46-year-old male with right infratemporal meningioma, pre and post tumour debulking.

Findings: T1-weighted axial MR images with gadolinium. (A) preoperative image, showing lobulated, enhancing infratemporal tumour (arrow) with small enhancing intradural component (asterisk). (B) Post tumour debulking shows absent/ removed right infratemporal extracranial component. The right temporal intradural component remains relatively similar.

Technique: 1.5 Tesla Siemens Magnetom Symphony scanner. (A) Axial T1W with gadolinium, TR 470, TE 8.7, 5.0mm slice thickness, contrast material Magnevist (5mls) ; (B) Axial T1W with gadolinium, TR 590, TE 11, 5.0mm slice thickness, contrast material Magnevist (5mls). 


\begin{tabular}{|l|l|l|}
\hline GRADE & STRUCTURES EXCISED & $\begin{array}{l}\text { RECURRENCE RATE } \\
\text { IN 10 YEARS }\end{array}$ \\
\hline $\mathbf{1}$ & Complete macroscopic removal of tumour, dural attachment and abnormal bone & $9 \%$ \\
\hline $\mathbf{2}$ & $\begin{array}{l}\text { Complete macroscopic removal of tumour and visible attachments with coagulation of } \\
\text { dural attachment }\end{array}$ & $19 \%$ \\
\hline $\mathbf{3}$ & $\begin{array}{l}\text { Complete removal of tumour, without resection or coagulation of its dural } \\
\text { attachment/extradural component }\end{array}$ & $29 \%$ \\
\hline $\mathbf{4}$ & Partial removal - residual intradural tumour insitu & $39 \%$ \\
\hline $\mathbf{5}$ & Simple decompression, with or without biopsy & Not documented \\
\hline
\end{tabular}

Table 1: Simpson surgical excision grading and rate of recurrence $(7,8)$.

\begin{tabular}{|c|c|}
\hline ETIOLOGY & Acquired; originates from meningocytes or arachnoid cap cells \\
\hline INCIDENCE & Rare; accounts for up to $2 \%$ of all meningiomas \\
\hline GENDER RATIO & Female : male approximately $2: 1$ \\
\hline $\begin{array}{l}\text { AGE } \\
\text { PREDILECTION }\end{array}$ & $40-60$ year old \\
\hline RISK FACTORS & Ionizing radiation, hormones \\
\hline $\begin{array}{l}\text { IMAGING } \\
\text { FINDINGS }\end{array}$ & $\begin{array}{l}\text { Avidly enhancing tumours with both intradural and extradural components. } \\
\text { CT: tumour isodense to brain parenchyma. } \\
\text { MRI: T1W and T2W isointense to grey matter with avid, homogenous contrast enhancement } \\
\text { Hyperostosis of adjacent bone. }\end{array}$ \\
\hline TREATMENT & $\begin{array}{l}\text { Surgical resection. Radiotherapy and radiofrequency ablation can be performed prior to surgery for large } \\
\text { tumours. }\end{array}$ \\
\hline PROGNOSIS & Associated with high rate of recurrence \\
\hline
\end{tabular}

Table 2: Summary table for extracranial meningioma. 


\begin{tabular}{|c|c|c|c|c|}
\hline Differential diagnosis & Radiograph & $\begin{array}{l}\text { Computed } \\
\text { tomography }\end{array}$ & MRI & $\begin{array}{l}\text { Best treatment } \\
\text { option }\end{array}$ \\
\hline $\begin{array}{l}\text { Extracranial } \\
\text { meningioma }\end{array}$ & $\begin{array}{l}\text { Hyperostosis of } \\
\text { bone overlying } \\
\text { tumour. } \\
\text { - Calcification may } \\
\text { be present }\end{array}$ & $\begin{array}{l}\text { Well defined, } \\
\text { isodense intradural } \\
\text { tumour with presence } \\
\text { of dural tail. Similar } \\
\text { appearing extradural } \\
\text { component. } \\
\text { - Avid contrast } \\
\text { enhancement. }\end{array}$ & $\begin{array}{l}\text { - Intradural and } \\
\text { extradural components } \\
\text { are isointense on T1W } \\
\text { and T2W with avid, } \\
\text { homogenous } \\
\text { enhancement }\end{array}$ & $\begin{array}{l}\text { - Surgical resection. } \\
\text { - Radiotherapy/ } \\
\text { - radiofrequency } \\
\text { ablation to reduce } \\
\text { large tumour bulk. }\end{array}$ \\
\hline $\begin{array}{l}\text { Solitary fibrous } \\
\text { tumour/ } \\
\text { hemangiopericytoma: } \\
\text { Grade I (previously } \\
\text { known as solitary } \\
\text { fibrous tumour) }\end{array}$ & - Bony erosions & $\begin{array}{l}\text { Well defined, } \\
\text { hyperdense extra- } \\
\text { axial mass. } \\
\text { - Variable calcification } \\
\text { and bony erosions. }\end{array}$ & $\begin{array}{l}\text { - Isointense on T1W. } \\
\text { - Heterogenous on T2W } \\
\text { giving 'yin-yang' } \\
\text { appearance with } \\
\text { heterogenous } \\
\text { enhancement. }\end{array}$ & $\begin{array}{l}\text { - Surgical resection. } \\
\text { - Radiotherapy for } \\
\text { incomplete } \\
\text { resection or } \\
\text { recurrence. }\end{array}$ \\
\hline $\begin{array}{l}\text { Grade II (previously } \\
\text { known as } \\
\text { hemangiopericytoma) }\end{array}$ & $\begin{array}{l}\text { - Aggressive bony } \\
\text { erosions/ } \\
\text { - destruction }\end{array}$ & $\begin{array}{l}\text { - Well defined, } \\
\text { hyperdense mass } \\
\text { with heterogenous } \\
\text { enhancement. }\end{array}$ & $\begin{array}{l}\text { - Isointense on } \mathrm{T} 1 \mathrm{~W} \text { and } \\
\mathrm{T} 2 \mathrm{~W} \text { with heterogenous } \\
\text { enhancement. } \\
\text { - Prominent internal flow } \\
\text { voids }\end{array}$ & $\begin{array}{l}\text { - Preoperative } \\
\text { embolization with } \\
\text { surgical resection }\end{array}$ \\
\hline Dural metastases & $\begin{array}{l}\text { Osteolytic, } \\
\text { sclerotic, or mixed } \\
\text { pattern of lesions, } \\
\text { depending on } \\
\text { primary tumour }\end{array}$ & $\begin{array}{l}\text { - Ill defined, extra- } \\
\text { axial tumours. }\end{array}$ & $\begin{array}{l}\text { - Iso-hypointense on } \mathrm{T} 1 \mathrm{~W} \text {, } \\
\text { iso-hyperintense on } \mathrm{T} 2 \mathrm{~W} \\
\text { with vivid contrast } \\
\text { enhancement }\end{array}$ & $\begin{array}{l}\text { - Primarily } \\
\text { radiotherapy. } \\
\text { - Surgical resection } \\
\text { of solitary, } \\
\text { resectable } \\
\text { tumours. } \\
\text { - Chemotherapy }\end{array}$ \\
\hline Dural lymphoma & $\begin{array}{l}\text { Osteolytic lesions } \\
\text { with permeative } \\
\text { pattern }\end{array}$ & $\begin{array}{l}\text { Fairly well defined, } \\
\text { hyperdense, extra- } \\
\text { axial tumours with } \\
\text { vasogenic edema. }\end{array}$ & $\begin{array}{l}\text { - Isointense on } \mathrm{T} 1 \mathrm{~W} \text { and } \\
\text { iso-hypointense on } \mathrm{T} 2 \mathrm{~W} \\
\text { with homogenous } \\
\text { enhancement. }\end{array}$ & $\begin{array}{l}\text { - Surgery and } \\
\text { radiotherapy }\end{array}$ \\
\hline $\begin{array}{l}\text { Neurosarcoidosis } \\
\text { (dural involvement) }\end{array}$ & $\begin{array}{l}\text { - May show well } \\
\text { circumscribed } \\
\text { "punched out" } \\
\text { lesions with } \\
\text { nonsclerotic } \\
\text { margins }\end{array}$ & $\begin{array}{l}\text { Diffuse dural } \\
\text { thickening or focal } \\
\text { dural masses appear } \\
\text { hyperdense. } \\
\text { - Hydrocephalus may } \\
\text { be present. }\end{array}$ & $\begin{array}{l}\text { - Isointense on } \mathrm{T} 1 \mathrm{~W} \text { and } \\
\text { predominantly } \\
\text { hypointense on } \mathrm{T} 2 \mathrm{~W} \\
\text { with homogenous } \\
\text { enhancement }\end{array}$ & - Steroid therapy \\
\hline
\end{tabular}

Table 3: Differential diagnosis table for extracranial meningioma. 


\section{ABBREVIATIONS}

$\mathrm{CNS}=$ Central nervous system

$\mathrm{CT}=$ Computed tomography

GRE $=$ Gradient echo

MALT $=$ Mucosa associated lymphoid tissue

MRI = Magnetic resonance imaging

MRS = Magnetic resonance spectroscopy

NAA $=$ N-Acetylaspartase

SFT $=$ Solitary fibrous tumour

SWI = Susceptibility weighted imaging

\section{KEYWORDS}

Extracranial; Meningioma; Temporal; CT scan; MRI scan

\section{ACKNOWLEDGEMENTS}

Department of Neurosurgery and Department of Radiology, Sungai Buloh Hospital, Malaysia. The authors would also like to thank the Director of Health Malaysia for permission to publish this paper.

\section{Online access}

This publication is online available at:

www.radiologycases.com/index.php/radiologycases/article/view/3898

\section{Peer discussion}

Discuss this manuscript in our protected discussion forum at: www.radiolopolis.com/forums/JRCR

\section{Interactivity}

This publication is available as an interactive article with scroll, window/level, magnify and more features.

Available online at www.RadiologyCases.com

\section{Published by EduRad}

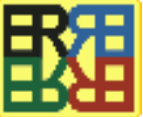

www.EduRad.org 